\title{
T-cell Non-Hodgkin lymphoma associated with myelodysplasia: A case
}

\section{report in a child}

\section{Gokce Pinar Reis ${ }^{1}$, Aysenur Bahadir ${ }^{1}$, Erol Erduran ${ }^{1}$}

\begin{abstract}
Myelodysplastic syndrome (MDS) is a clonal bone marrow disease characterized by ineffective erythropoiesis. MDS patients have also cytopenia. The risk of acute leukemia, and particularly of acute myeloblastic leukemia (AML), is the most important characteristic of the disease .

Myelodysplasia associated with Non Hodgkin's lymphomas (NHL) has been rarely described in the literature. This is suggested to be due to the defect in the immune system, an up-regulation of some cytokines, and a common molecular origin.

In this article, we reported a 7-year-old pediatric NHL case with a normal karyotype and myelodysplasia in the bone marrow and discussed the pathogenesis of the association of NHL and myelodysplasia.
\end{abstract}

Keywords: Lymphoma, myelodysplasia, relation

\section{Introduction}

Myelodysplastic syndrome (MDS) is a clonal bone marrow disease characterized by ineffective erythropoiesis. MDS patients have cytopenia. The risk of acute leukemia, and particularly of acute myeloblastic leukemia (AML), is the most important characteristic of the disease (1).

MDS is defined as primary of de novo MDS if it develops in a child who has no other diseases, and who has not received chemotherapy or radiotherapy for any other reason, while it is considered as secondary MDS if there is a factor which promotes the development of myelodysplasia, especially a history of chemotherapy or radiotherapy (2).

Genetic factors, ionized radiation, chemotherapy, benzene, smoking, alcohol, hair dyes and over-consumption of foods especially rich in phenol are risk factors for the development MDS (2).

In primary MDS cases, cytogenetic abnormalities are found in $50-70 \%$ of the patients, while this rate rises over $85 \%$ in cases with treatment-related secondary MDS (2).

Non-Hodgkin's lymphomas (NHL) are a group of malignant diseases originating in the organs and cells of the immune system. Childhood NHL exhibits diffuse and extranodal involvement. Childhood NHL generally arises from lymphoid precursors and B-cell type is found in $80 \%$ of the cases (3).
Non-Hodgkin's lymphomas typically metastasize early and the risk of leukemic presentation and central nervous system relapse is high in NHLs (4).

Myelodysplasia associated with NHL has been rarely described in the literature. This is suggested to be due to the defect in the immune system, an up-regulation of some cytokines, and a common molecular origin (5-10).

In this article, we reported a 7-year-old pediatric NHL case with a normal karyotype and myelodysplasia in the bone marrow and discussed the pathogenesis of the association of NHL and myelodysplasia.

\section{Case}

A 7-year-old female patient admitted with a swelling on the right side of the neck which had been noted 5 days ago. She had had no complaints such as fever, weight loss, or night sweating. The past medical history and family history of the patient revealed no significant findings. The physical examination of the patient revealed multiple lymphadenopathies in both cervical chains in the submandibular region, with the largest on the left measuring $2.5 \times 1.5 \mathrm{~cm}$ and the largest on the right measuring $3.5 \times 1.5 \mathrm{~cm}$, and a $2 \times 2 \mathrm{~cm}$ lymphadenopathy in the right inguinal region. 
The laboratory examinations revealed a hemoglobin value of $10.1 \mathrm{~g} / \mathrm{dl}$, a WBC count of $1.2 \times 109 / 1$, and a platelet count of 159x109/1 . Peripheral blood smear revealed no blasts. The lactate dehydrogenase $705 \mathrm{U} / \mathrm{l}$ and B 12 levels and the other biochemical test results were considered as normal. The immunoglobulin A $133.0 \mathrm{mg} / \mathrm{dl}, \mathrm{G} 955.0 \mathrm{mg} / \mathrm{dl}, \mathrm{M}$ $44.0 \mathrm{mg} / \mathrm{dl}$ and E $49.25 \mathrm{IU} / \mathrm{ml}$ levels were consistent with the age of the patient.

The results of the direct Coombs's test and the ELISAbased Parvovirus PCR, EBV, and CMV assays were negative.

Abdominal ultrasonography revealed multiple ovoid and round lymphadenopathies with loss of echogenic hilus in the para-aortic, parailiac and mesenteric regions, with the largest measuring $21 \times 13 \mathrm{~mm}$ and neck ultrasonography revealed multiple reactive lymphadenopathies with echogenic hilus and hilar blood flow in both cervical chains in the submandibular region, with the largest one on the left measuring $23 \times 10 \mathrm{~mm}$ and the largest one on the right measuring $32 \times 14 \mathrm{~mm}$.
The bicytopenia of the patient continued for 4 days in the clinical follow-up and bone marrow aspiration was performed. The bone marrow aspiration smear revealed $4 \%$ monocytes, 35\% normoblasts, 30\% lymphocytes, $15 \%$ myelocytes, $6 \%$ metamyelocytes, $6 \%$ neutrophis, and $4 \%$ blasts. Dysplasia was found in bone marrow cells.

Diffuse hypogranular myeloid cells, dysplastic megakaryocytes and erythroblastic cells were observed (Figure 1a,1b,1c). The cervical lymph node biopsy result was consistent with diffuse NHL with a high-grade malignancy (Figure 2).

Immunohistochemical examination of cervical lymph node was consistent with T-cell. Analyses of 17p13.1, p53, 20q12, 5q31, 7q31 gene deletions and monosomy/trisomy 7 , and monosomy/trisomy 8 chromosomes were performed with bone marrow cytogenetic and FISH (fluorescence in situ hybridization) studies. The results were accepted as normal. The patient left our hospital to continue her diagnostic studies and treatment in another institution.

The cervical lymph node biopsy result was consistent with diffuse NHL with a high-grade malignancy (Figure 2).

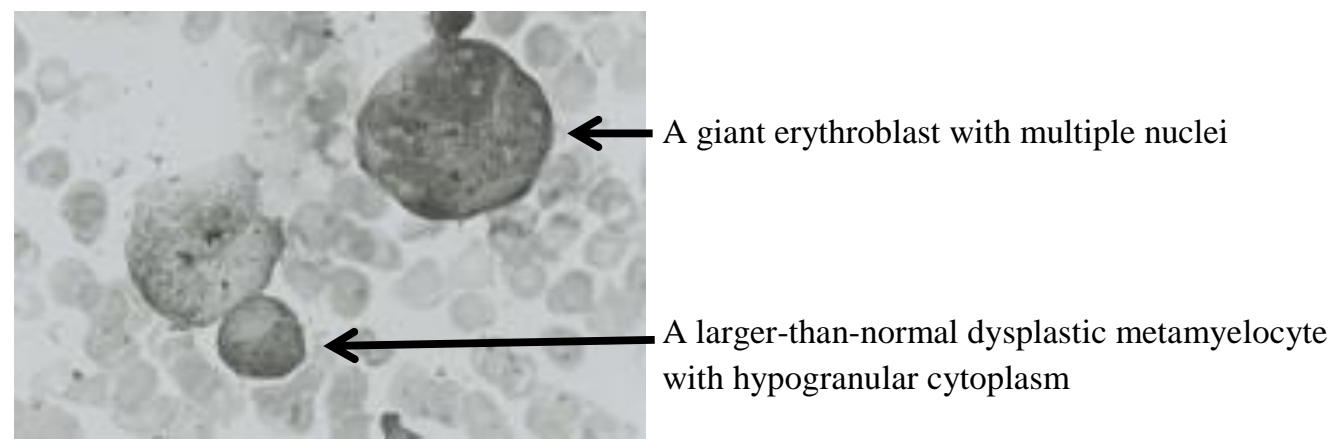

Figure 1A: A giant erythroblast with multiple nuclei and a larger-than-normal dysplastic metamyelocyte with hypogranular cytoplasm

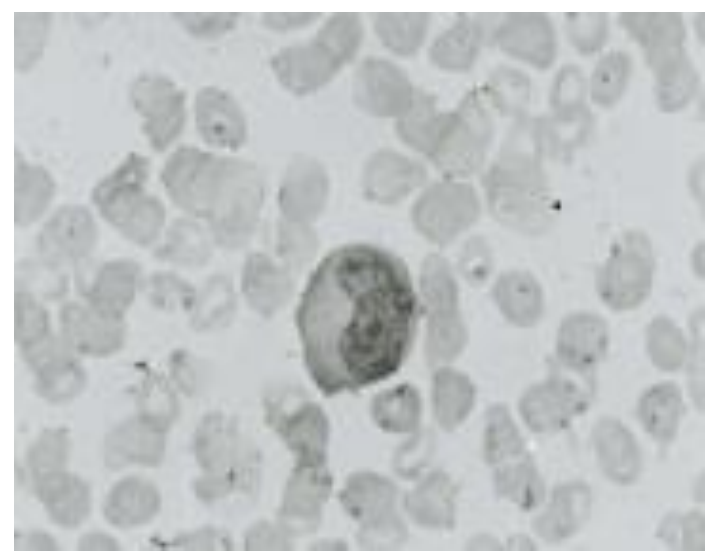

Figure 1B: A hypogranular metamyelocyte

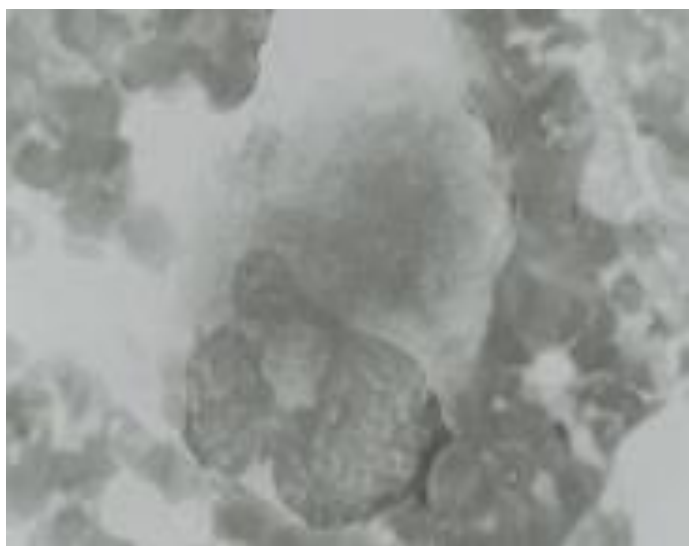

Figure 1C: A megakaryocyte with a pyknotic nucleus and a dysplastic appearance 


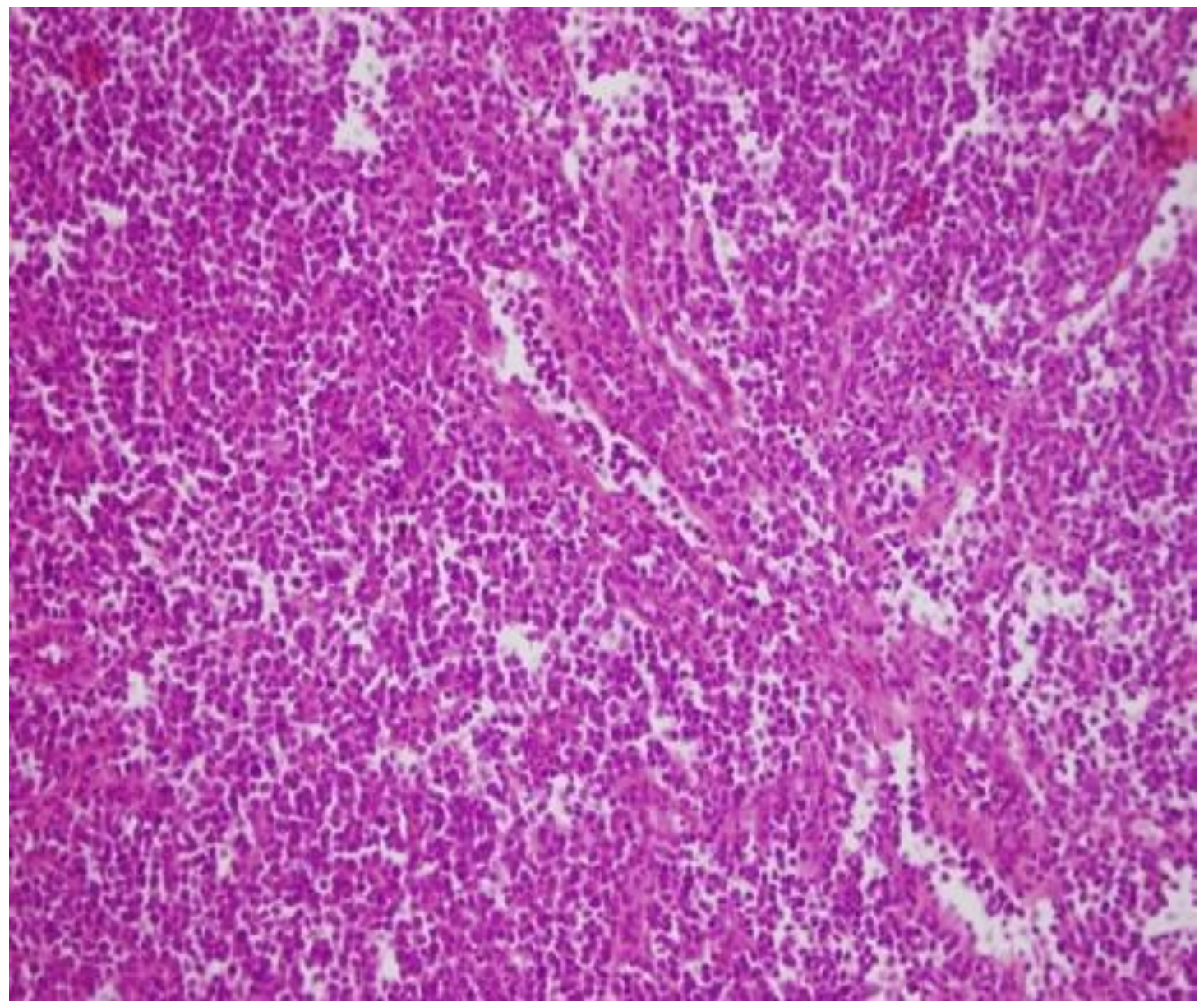

Figure 2: Diffuse NHL with high-grade malignancy

Immunohistochemical examination of cervical lymph node was consistent with T-cell. Analyses of 17p13.1, p53, 20q12, 5q31, 7q31 gene deletions and monosomy/trisomy 7 , and monosomy/trisomy 8 chromosomes were performed with bone marrow cytogenetic and FISH (fluorescence in situ hybridization) studies. The results were accepted as normal. The patient left our hospital to continue her diagnostic studies and treatment in another institution.

\section{Discussion}

MDS is known to be related to a process in tumor differentiation. A high incidence of MDS was reported in relation with solid tumors, such as lung, colon, prostate and liver cancers (11). The same relationship was described between MDS and lymphoid neoplasms, such as acute lymphoblastic leukemia, chronic lymphocytic leukemia, and NHL (12-15). In 1996, a group of Spanish investigators studied the association of lymphoid malignancy in patients with primary MDS and found an association rate of only $1 \%$ and concluded that this association could be a coincidence (14).

The association of MDS and lymphoma was described in 21 cases in the literature. However, in 9 of these 21 cases MDS and NHL were diagnosed simultaneously.
In 12 cases, MDS diagnosis was made primarily before the onset of lymphoma and the time between the two diseases ranged between 5 months and 4 years $(5,13,16-27)$.

The mechanisms responsible for the development of NHL in MDS patients have not been cleared yet. MDS is generally considered as a clone disorder with pluripotent stem cell origin and with a potential to differentiate into lymphoid and myeloid cells. Some authors suggest that the two diseases are caused by the same neoplastic process or a common origin (6).

Another opinion is that MDS plays a predisposing role in the development of lymphoid neoplasms. (5). MDS is associated with abnormal immunological functions. Abnormal lymphocyte count and function (especially natural killer cells) induce growth of neoplastic cells. The immune system defect underlying the development of myelodysplasia is also present in NHL $(8,9)$.

Shimanoto et al. related the association of MDS and NHL to the up-regulation of particular cytokines, such as IL-6 and vascular endothelial growth factor (VEGF) and reported a case of anaplastic large-cell lymphoma with presence of high IL-6 and VEGF levels and bone marrow myelodysplasia at the time of diagnosis (10).

Chromosomal anomalies are common in both MDS and lymphomas. The questions, whether there are other 
cytogenetic abnormalities not known yet, and whether the association of MDS with NHL is caused by these common cytogenetic anomalies, still remain to be answered.

In 1998, Mori A et al. found bone marrow dysplasia simultaneously with the diagnosis of angiocentric lymphoma in a 46-year-old male patient. They thought that the association might be caused by cytokines, such as interleukin-2, -4, and-6 (28).

Huang $\mathrm{HH}$ et al. also reported a case with the association of bone marrow dysplasia and lymphoma in 2009. They suggested that this association might be caused by a common chromosomal anomaly (del (20q)) based on the fact that the patient had 20q deletion in both myeloid and lymphoid cell lines (29).

\section{Conclusion}

In conclusion, the association of MDS and lymphoma is very rare. Only 21 cases have been reported to date. However, de novo MDS and lymphoma were simultaneously identified in 8 of these cases. We think that this association may be caused by a common molecular origin, common chromosomal anomalies and cytokines. Large scale studies including many cases are needed on this subject.

\section{Acknowledgments, Funding: None}

Conflict of Interest: The authors declare no potential conflicts of interest with respect to the research, authorship, and/or publication of this article.

Author's Contributions: GPR, AB, EE: Research concept and design; Patient examination, data collecting, histochemical, biochemical analysis and interpretation of data. GPR: Preparation of article and revisions. All authors approved the final version of the manuscript,

Ethical issues: All Authors declare, Originality and ethical approval of research. Responsibilities of research, responsibilities against local ethics commission are under the Authors responsibilities. The study was conducted under defined rules by the Local Ethics Commission guidelines and audits.

\section{References}

1. Steensma DP, Tefferi A. The myelodysplastic syndrome (s) : a perspective and review highligh-ting current controversies. Leuk Res. 2003; $27: 95-120$

2. Elghetany MT.Myelodysplastic syndromes in children: a critical review of issues in the diagnosis and classification of 887 cases from 13 published series. Arch Pathol Lab Med. 2007;131:1110-6

3. Link MP and Weinstein HJ: Malignant No-Hodgkin Lymphomas in children.In:Pizzo PA, Poplark DG, eds. Principles and Practive of Pediatric Oncology.Fifth Edition, Lippincott Williams and Wilkins, Philedelphia, 2006, pp:722-747
4. Percy $C L$, Smith $M A$, Linet $M$, et al. Lymphomas and reticuloendothelial neoplasms. In: Ries LAG, Smith MA, Gurney JG, et al., eds. Canser indicence and survival amon children and adolescents. United States SEER Program 1975-1995. Bethesda, MD: National Cancer Institute, SEER Program. NIH Pub. No. 99-4649, 1999:35-49.

5. Uematsu $M$, Ochi $H$, Ueda $Y$, et al: Coexistent myelodysplastic syndrome and Non-Hodgkin's lymphoma. Report of a case and review of the literature. Int J Hematol 1995;62:45-51.

6. Weimar IS, Bourhis JH, De Gast GC, et al: Clonality in myelodysplastic syndrome. Leuk Lymphoma 1994;13:215-221.

7. Brezinova J, Zemanova Z, Randsdorfova S, et al: Prognostic significance of del(20q) in patients with hematological malignancies. Cancer Genet Cytogenet 2005;160:188-192.

8. Bynoe AG, Scott CS, Ford $P$, et al: Decreased $T$ helper cells in the myelodysplastic syndromes. Br J Haematol 1983;54:97-102.

9. Colombat PH, Renoux M,Lamagnere JO, et al: Immunologic indices in myelodysplastic syndromes. Cancer 1988;61:1075-1081.

10. Shimamoto $T$, Hayashi $S$, Ando $K$, et al: Anaplastic large-cell lymphoma which showed severe inflammatory status and myelodysplasia with increased VEGF and IL-6 serum levels after long-term immunosuppressive therapy. Am J Hematol 2001;66:4952

11. Fong GH, Rossant J, Gertsenstein M, et al: Role of the Flt-1 receptor tyrosine kinase in regulating the assembly of vascular endothelium. Nature 1995;376:66-70.

12. Abruzzese $E$, Buss $D$, Rainer $R$, et al: Progression of $a$ myelodysplastic syndrome to pre-B lymphoblastic leukemia. A case report and cell lineage study. Ann Hematol 1996;73:35-38.

13. Copplestone JA, Mufti GJ, Hamblin TJ, et al: Immunologic abnormalities in myelodysplastic syndromes II. Coexistent lymphoid or plasma cell neoplasms. A report of 20 cases unrelated to chemotherapy. Br J Haematol 1986;63:149-159.

14. Florensa L, Vallespi $\mathrm{T}$, Woessner $\mathrm{S}$, et al: Incidence and characteristics of lymphoid malignancies in untreated myelodysplastic syndromes. Leuk Lymphoma 1996;23:609-612.

15. Hamblin TJ: Immunologic abnormalities in myelodysplastic syndromes. Semin Hematol 1996;3:150-162.

16. Anzai $T$, Hirose $W$, Nakane $H$, et al: Myelodysplastic syndrome associated with immunoblastic lymphadenopathy-like T-cell lymphoma: simultaneous clinical improvement with chemotherapy. Jpn J Clin Oncol 1994;24:106-110.

17. Takaku T, Miyazawa K, Sashida G, et al: Hepatosplenic $\alpha \beta$ T- cell lymphoma with myelodysplastic syndrome. Int J Hematol 2005;82:143-147.

18. Xu B, Meng FY, Li YQ T- cell non-Hodgkin lymphoma with myelodysplastic syndrome: A case report. Zhonghua Zhong Liu Za Zhi 2005;27:320.

19. Sato $\mathrm{T}$, Shiga $\mathrm{Y}$, Takeda $\mathrm{H}$, et al: IBL-like T-cell lymphoma with helper T-cell phenotype in a case of myelodysplastic syndrome. Rinsho Ketsueki 1986;27:612-616. 
20. Auger MJ, Nash JRG, Mackie MJ, et al: Marrow involvement with T cell lymphoma initially presenting as abnormal myelopoiesis. J Clin Pathol 1986;39:134-137.

21. Kawashima K, Furukawa Y, Akutu M, et al: Primary non- Hodgkin's lymphoma, small lymphocytic type, in the spleen complicating myelodysplastic syndrome. J Jpn Soc Intern Med 1988;77:10511055.

22. Breccia M, Petti MC, D’Elia GM, et al: Cutaneous pleomorphic T-cell lymphoma coexisting with myelodysplastic syndrome transforming into acute myeloid leukemia: Successful treatment with a fludarabine-containing regimen. Eur J Haematol 2002;68:1-3.

23. Dalamaga M, Karmaniolas K, Chavelas C, et al: Coexistence of primary refractory anemia with ringed sideroblasts and T-cell lymphoblastic non- Hodgkin lymphoma. Acta Haematol 2004;111:171-172.

24. Cheng HB, Luo MZ, Zhang SM: A case of acute myelomonocytic leukemia transformed from myelodysplastic syndrome coincident with malignant lymphoma. Mod Diagn Treat 2004;15:191.
25. Liu GX, Li X: Coexistence of myelodysplastic syndrome and malignant lymphoma in the peritoneal cavity: a case report. Henan Zhong Liu Xue Za Zhi 2001;14:172.

26. Rostoker G, Raphael M, Boisnick S, et al: Coexistence of Sezary syndrome and dysmyelopoiesis with an excess of myeloblasts. J Am Acad Dermatol 1986;15:1296-1298.

27. Kazakov DV, Mentzel T, Burg G, et al: Blastic natural killer-cell lymphoma of the skin associated with myelodysplastic syndrome or myelogenous leukaemia: A coincidence or more? $\mathrm{Br} J$ Dermatol 2003;149:869-876.

28. Mori A, Hashino S, Imamura M, et al: Bone marrow dysplasia with basophilic cells in a patient with angiocentric lymphoma. Acta Haematol.1998;99(2):98-101.

29. Huang HH, Zhu JY, Han JY, et al: Co-existent de novo myelodysplastic syndrome and T-cell non- Hodgkin lymphoma: a common origin or not? J Int Med Res. 2009 Jan-Feb;37(1):270-6

Copyright (C) 2018 The Author(s); This is an open-access article distributed under the terms of the Creative Commons Attribution License (http://creativecommons.org/licenses/by/4.0), which permits unrestricted use, distribution, and reproduction in any medium, provided the original work is properly cited. All Rights reserved by international journal of Medical Science and Discovery. 